\title{
A Strange Atypical Spitz Tumor
}

\author{
Andrea Bassi ${ }^{1}$, Vincenzo Piccolo ${ }^{2}$, Maurizio de Martino ${ }^{1}$, Teresa Oranges ${ }^{1}$, \\ Cesare Filippeschi ${ }^{1}$, Giuseppe Argenziano ${ }^{2}$
}

1 Department of Health Sciences, University of Florence \& Department of Paediatric Medicine, Anna Meyer Children's University Hospital, Florence, Italy

2 Dermatology Unit, University of Campania Luigi Vanvitelli, Naples, Italy

Key words: dermoscopy, Spitz tumor, histopathology, atypical Spitz tumor

Citation: Bassi A, Piccolo V, de Martino M, Oranges T, Filippeschi C, Argenziano G. A strange atypical Spitz tumor. Dermatol Pract Concept. 2019;9(3):237-238. DOI: https://doi.org/10.5826/dpc.0903a19

Accepted: February 12, 2019; Published: July 31, 2019

Copyright: @2019 Bassi et al. This is an open-access article distributed under the terms of the Creative Commons Attribution License, which permits unrestricted use, distribution, and reproduction in any medium, provided the original author and source are credited.

Funding: None.

Competing interests: The authors have no conflicts of interest to disclose.

Authorship: All authors have contributed significantly to this publication.

Corresponding author: Vincenzo Piccolo, MD, c/o II Policlinico, Edificio 9, Primo piano, Via Pansini 5 - 80131 Napoli, Italy. Email: piccolo.vincenzo@gmail.com

An 8-year-old boy presented with a well-demarcated pigmented lesion localized $5 \mathrm{~cm}$ above his right knee. His parents reported that it had appeared approximately 5 months before as a small pink-red papule initially diagnosed as a wart. Gradually, the lesion grew in size and developed a darker area in the center (Figure 1).
Dermoscopically, the lesion showed a multicomponent pattern with blue to black dots and globules, blue-white veil, and pinkish color, especially visible at the periphery (Figure 2). Histological evaluation revealed a well-circumscribed dermoepidermal pigmented atypical melanocytic proliferation composed of epithelioid spindle cells (spitzoid cytology).
Figure 1. Small pink-red papule on the right knee $(0.8 \times 1 \mathrm{~cm})$ with a cross shape distribution of the pigment. [Copyright: @2019 Bassi et al.]
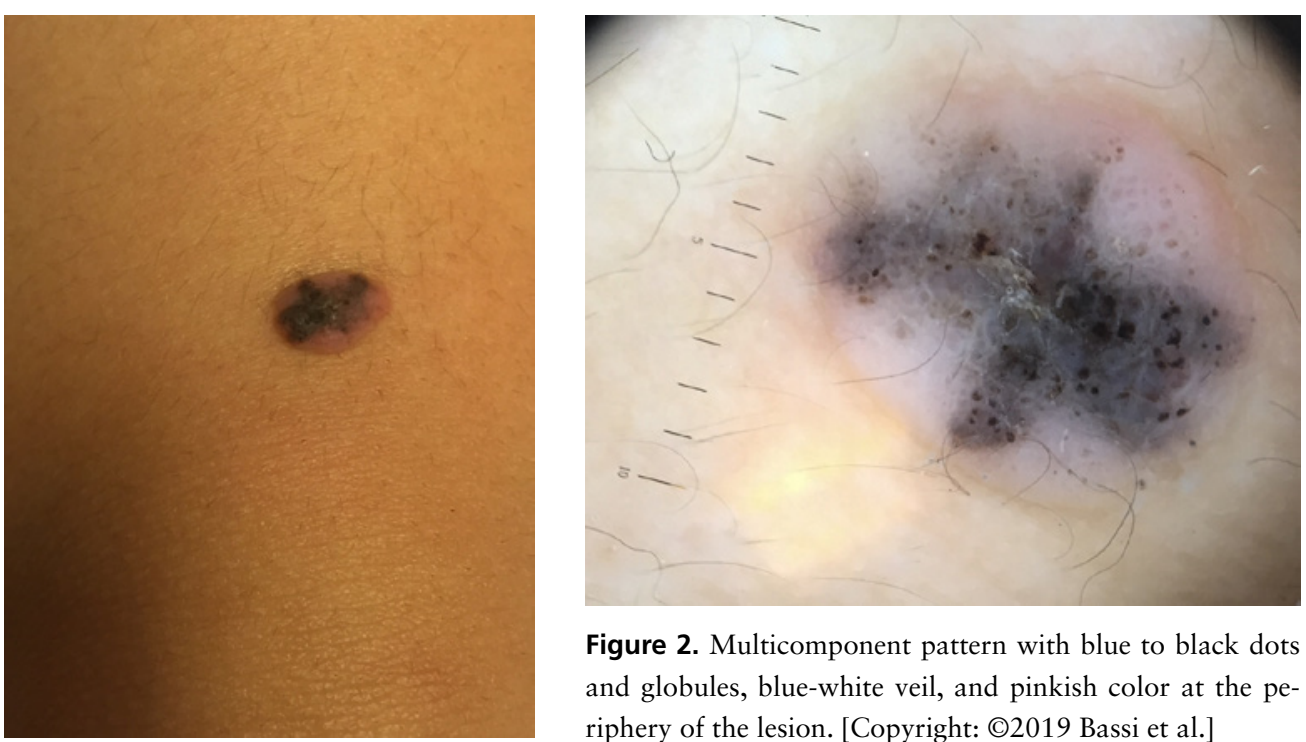

Figure 2. Multicomponent pattern with blue to black dots and globules, blue-white veil, and pinkish color at the periphery of the lesion. [Copyright: (C2019 Bassi et al.] 

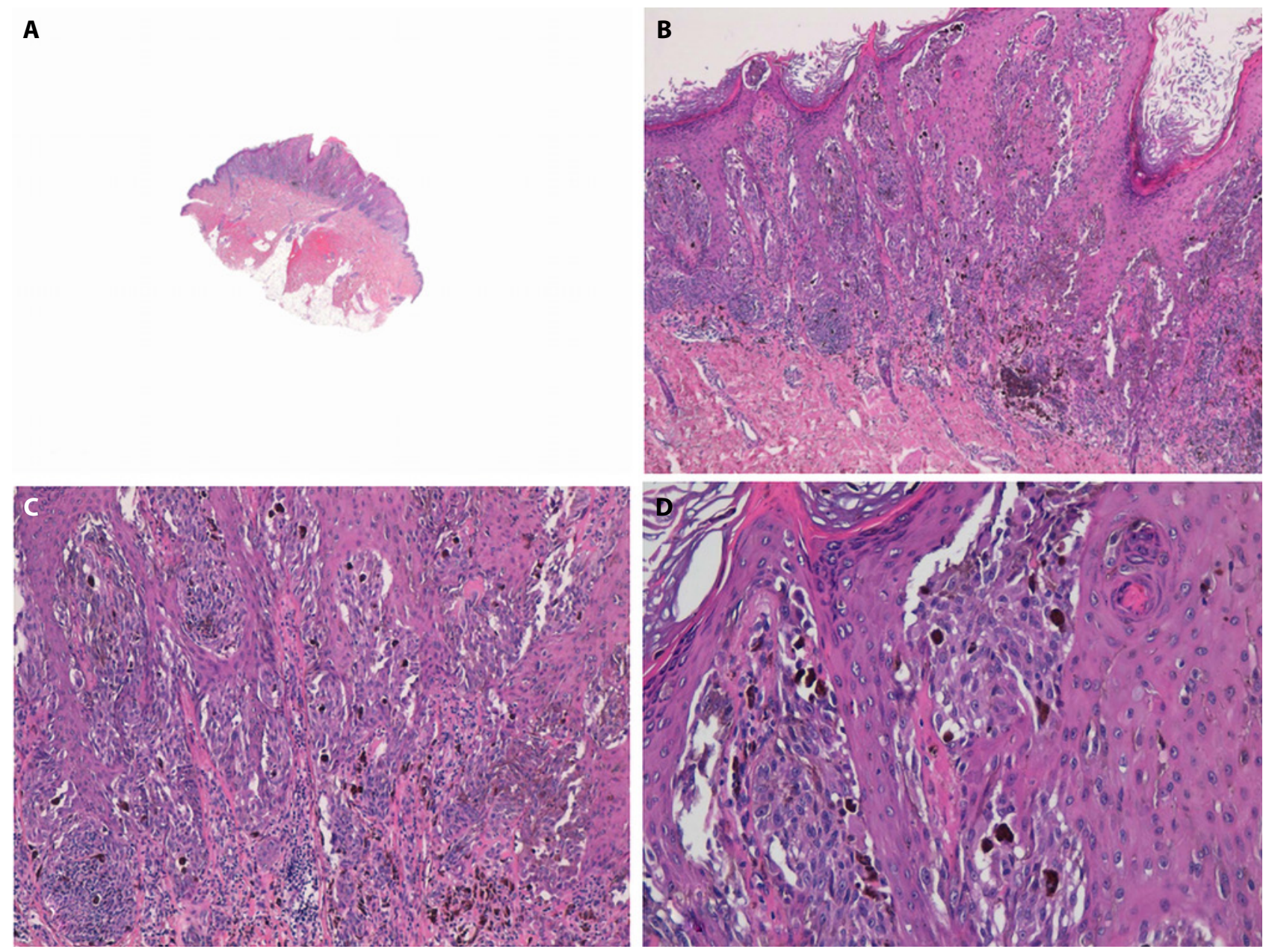

Figure 3. (A) Histopathological examination shows a raised, well-circumscribed, slightly asymmetric dermoepidermal atypical melanocytic proliferation associated with marked hyperkeratosis and irregular hyperplasia (H\&E, original magnification $\times 2.5)$. (B) There is prominent central and lateral pagetoid spread of melanocytes and no epidermal ulceration (H\&E, original magnification $\times 10)$. (C) Pigmented melanocytes display an epithelioid spindle (spitzoid) morphology and are mostly arranged in confluent fascicles with peripheral retraction artifacts (H\&E, original magnification $\times 20)$. (D) Melanocytes show mild pleomorphism and are intermingled with numerous melanophages (H\&E, original magnification $\times 40)$. H\&E = hematoxylin and eosin. [Copyright: $\odot 2019$ Bassi et al.]

Melanocytes were mostly arranged in confluent fascicles, with retraction artifacts. There was prominent central and lateral pagetoid spread (Figure 3). A final diagnosis of atypical Spitz tumor (AST), with free margins, was made.

ASTs have been regarded as "borderline" melanocytic lesions with overlapping features with Spitz nevus and spitzoid melanoma, but their true biological significance is still poorly understood. Pediatric ASTs seem to be associated with minimal lethal potential. In our case the clinical diagnosis was not straightforward; the site and the patient's age led us to suspect initially a Spitz with an atypical presentation
[1]. The atypical dermoscopy presentation and the atypical melanocytic proliferation of spitzoid cells led us to the final diagnosis. Given the complexities in interpretation, great care should be given when dealing with spitzoid lesions that show any degree of deviation from the classic features of Spitz nevus.

\section{Reference}

1. Moscarella E, Piccolo V, Argenziano G, et al. Problematic lesions in children. Dermatol Clin. 2013;31(4):535-547. 